\title{
Integrated Permitting System and Waste Sector: An Analysis of Mediterranean Regions
}

\author{
Maria Rosa De Giacomo, Tiberio Daddi \\ Institute of Management \\ Scuola Superiore Sant'Anna \\ Pisa, Italy
}

\begin{abstract}
Integrated permits address every aspect of a facility's operation that has an environmental impact. Permitting industrial facilities is a key tool for regulating environmental pollution in many nations across the globe. In Europe, the integrated approach on environmental pollution is based on the Integrated Pollution Prevention and Control Directive (61/1996), recently replaced by Industrial Emissions Directive (75/2010). The Directive covers about 50,000 facilities in Europe. The implementation of the Directive could differ greatly among European regions due to the different competent authorities involved. The study aims to assess how the IPPC Directive impacts the management of industrial landfill companies. The aim of the paper is to investigate how the implementation of the Directive in six European regions could have a different impact on companies in the same sector. This objective is pursued through the analysis of 61 permits issued in six different Mediterranean regions In addition, this study also includes the analysis of fees that companies have to pay for the administrative and control procedures. Results of the study show that some of the differences in the implementation of the IPPC Directive cannot always be justified by the flexibility provided by the legislation.These differences affect the application of the Directive in different ways, causing differences in the subsequent prevention of pollution, the key principle of the Directive. The results show how a higher level of coordination among the different competent authorities could be a solution to overcome this situation.
\end{abstract}

\section{Introduction}

An integrated approach to permitting is more than just a consolidation or a "stapling together" of single-media permits. Integrated permits address every aspect of a facility's operation that has an environmental impact. In most countries, permitting programs were first designed to separately opera tion that has an environmental impact. In most countries, permitting programs were first designed to separately address specific environmental elements (e.g. water, air, and land) or specific environmental concerns (e.g. smog or hazardous waste management and disposal). Under this type of system, a major facility might be granted a permit, or otherwise regulated, through a variety of different controls - even by different regulators. However, an increasing number of governments, most notably in the European Union (EU), have been transforming their industrial pollution permitting regimes to foster a more integrated approach.

In Europe, this approach is based on the Integrated Pollution Prevention and Control (IPPC) Directive. It was issued for the first time in 1996 [1] and was amended in 2008. Now it has been replaced by Industrial Emissions Directive (IED) no. 75/2010. The IPPC Directive represents one of the central policy tools of the European Union to regulate industrial activities and achieve a higher level of protection of the environment as a whole. More than 50,000 most polluting facilities are covered by the Directive and receive an integrated permit from their competent authorities. The Directive requires the competent authorities to issue a unique permit for those industrial installations where limits, monitoring frequencies and operational requirements exist for all environmental aspects (water emissions, air emissions, soil, etc.).

Generally speaking, the IPPC permitting system is a comprehensive, multi-media, pollution prevention approach to environmental protection that also promotes sustainable practices (e.g. consideration of consumption of water and raw materials, energy efficiency). The implementation of the IPPC system is based on a single standard-setting approach and on the evaluation of Best Available Techniques (BAT). In short, BAT are based on the most effective and advanced stage of techniques and their associated performance ranges. BAT are designed to achieve a high level of protection for the environment as a whole. In order to facilitate the determination of the BAT at each site, several European countries rely on 
a variety of cross-cutting tools that support standardsetting across all environmental media. A key concept of the IPPC Directive is the "flexibility principle." Through the permit issuance process, an IPPC permit writer fits plant-specific conditions (facility characteristics and local conditions) with sector-wide BAT indicated in the Best References Documents (BREFs). BREFs are the result of the information exchange process related to the BAT- for example, BAT-based numeric limits (known as Emission Limit Values - ELVs and derived from sector benchmarks) and may be adjusted in a permit to reflect local and site-specific conditions. This includes both BAT-based limits adjusted to reflect environmental quality standards or local geographic conditions (e.g. depletion of local aquifer) and facilityspecific characteristics and conditions (e.g. equipment and technology already in use at the facility). Using this approach, IPPC permitting is able to combine local and facility-specific conditions with sector-wide considerations.

The study is based on a research project financed by the European Commission. The project started in the year 2009 and finished in 2011. For this reason, our paper is not focused on the current Industrial Emission Directive, but on the previous one, the Integrated Pollution Prevention and Control (IPPC) Directive 96/61/EC.

In the framework of this innovative European environmental regulation, this paper aims to assess how the IPPC Directive impacts the environmental management of industrial companies. It describes the results of an empirical study carried out in the landfill sector, aiming to show how the implementation of the Directive in six European regions could have a different impact on companies in the same sector.

The following article is structured as follows: in the next section, the existing IPPC based studies are briefly introduced, then we define the research question and the method adopted. In section 3, the results of the research are discussed before closing the paper with sections for discussion and conclusions.

\section{Integrated permitting studies in litera- ture}

There are many studies in literature which evaluate the implementation of environmental policies and assess the effects of environmental regulation on the management of companies. However, few of them are concerned with the Integrated Pollution Prevention and Control (IPPC) Directive [2]. Papers dealing with the IPPC Directive mainly focus on Best Avai able Techniques (BAT) assessment and identification of the environmental performances of IPPC installations. With regard to BAT, some authors have proposed methods that could be adopted to identify and assess techniques. [3] describe a method to disseminate BAT in two industrial sectors (dairy and textile) in three Southern Mediterranean countries:
Egypt, Morocco and Tunisia. The paper of [4] presents an approach to the evaluation of BAT. Similar aims were included in the paper [5]. A methodology to define Emission Limit Values associated with Best Available Techniques for wastewater emissions was included in the paper [6]. Also, the study [7] includes a methodology that focuses on the evaluation of existing BAT techniques. The methodology is based on case studies in order to consider the local conditions of companies. [8] affirm, through the development of an operational decision tool, that firms should use not a single best available technique, but rather the best combination of several available techniques. The methods and tools for adopting a combination of BAT are also investigated in the paper [9]. Other studies deal with the implementation of BAT in a specific industrial sector included in the scope of the IPPC Directive. The study [10] focuses on the implementation of the IPPC Directive and the Reference Document on Best Available Techniques in a Turkish textile mill. The authors conclude that the implementation of Best Available Techniques is crucial to reducing the consumption of water and energy. [11] assess the implementation of BAT in a seafood facility while [12] analyse BAT in the adhesives application sector. In addition to the studies focused on

BAT, there are some papers dealing with the ability of the IPPC legislation to reduce pollution, thereby improving the environmental performance of companies. The effectiveness of the IPPC directive in Ireland's pharmaceutical sector was demonstrated by the study [13]. The authors affirmed that the integrated licensing system made it possible to avoid pollution in the industrial sector analysed. The study [14] describes the ability of EMSs to improve performance in some IPPC sectors. The paper [15] considered case studies of British, Finnish and Swedish industries and their regulatory bodies. The purpose was to contribute to the discussion on the potential of the IPPC Directive as a driver of eco-efficiency in those firms. The effects of the IPPC Directive on the environmental performance of Finnish pulp and paper mills were investigated by [16]. The authors concluded that emissions decreased for some parameters, even if performance of the sector did not show major changes during the period considered. The study [17] described a model to disseminate the CSR among companies located in industrial clusters of IPPC sectors, such as tanneries and paper production. In a theoretical framework, we can find several studies on BAT and environmental performance linked to the integrated permitting system adopted in Europe. Nevertheless, we are able to identify a gap in literature dealing with studies that analyse the requirements included in integrated permits and the impact of these requirements on the management of companies.

The aim of our paper is to fill this literature gap through a cross European regional analysis focused 
on the landfill sector. Starting from the contents of the permits, we intend to investigate not only the main requirements, monitoring frequencies, and emission limit values imposed on these companies, but also whether the application of the IPPC Directive differs in the European regions considered with regard to the requirement for different mandatory requirements. In order to analyse these differences, we will assess if they can be justified by the flexibility principle provided by the IPPC regulation.

\section{Research question and method}

This study shows the results of the analysis of the content of 61 IPPC permits issued for the landfills receiving more than 10 tonnes per day or with a total capacity exceeding 25000 tonnes, excluding landfills of inert waste. The permits were issued in six European regions: Andalusia (8 permits) and Valencia (7 permits) -Spain-, Tuscany (16 permits), Piedmont (21 permits) and Sicily (6 permits) -Italy-, and West Macedonia (3 permits) -Greece-. The research aimed to identify differences in environmental management requirements, monitoring frequencies and limit emissions imposed on installations in the same industrial sector, but with permits issued in the different European regions investigated. Given that all the regions analysed belong to the same European economic market, we can expect to find few differences among permits. These differences should be linked to local environmental characteristics and, in any case, should not be so significant as to impact the costs sustained by the companies analysed. So, our hypothesis for testing is that, even if the IPPC Directive allows some flexibility to the Member States (MS) in its implementation, this should not create significant disparities in the landfills located in the different EU regions considered in this study.

The method applied in this study is Content Analysis. Some literature studies define Content Analysis as a systematic, replicable technique for compressing parts of text into fewer content categories based on explicit rules of coding [18, 19, 20, 21].

The permits were collected and analysed during the years 2009 - 2011, as a part of the MED IPPC NET project (Network for strengthening and improving the implementation of the European IPPC Directive regarding Integrated Pollution Prevention and Control in the Mediterranean). MED IPPC NET was a 30 month-project, which was co-financed by the European Commission through the MED Programme. Permits were collected by project partners. Competent authorities issued permits in each of the regions considered which were involved. Competent authorities were also interviewed in order to investigate some aspects related to the issue of IPPC permits. For example, we also analysed some aspects related to the administrative and inspection systems related to the IPPC permit. In particular, we referred to fees that companies, covered by the IPPC Direc- tive, have to pay in the different regions. Moreover, we also focus on the on-site inspections planned.

Permits were procured in electronic format. The sample collected is small (61 observations), but this aspect could be justified by the very intensive commitment and effort of the partners to collect data. Indeed, even if article 15 of the IPPC Directive allows public access to information regarding the implementation of the Directive - as also indicated in the Aarhus convention- in some cases, the project partners encountered difficulties in freely accessing this kind of data. The main regions represented are Piedmont (34\% of the total number of permits) and Tuscany (26\%), followed by Andalusia (13\%), Valencia (11\%), Sicily (10\%) and West Macedonia $(5 \%)$. We collected data concerning six European regions and various competent authorities responsible for the issuance of integrated permits. The study population consists of 61 IPPC permits.

\section{Results}

\subsection{Best Available Techniques}

One of the aspects investigated in order to understand how the IPPC Directive has been implemented refers to the requirements indicated in permits about Best Available Techniques. The BREFs do not require the adoption of Emission Limit Values (ELVs) or specific techniques, but they are taken into account by the competent authorities when setting ELVs. In this sense, the BAT are considered a tool for competent authorities to implement the IPPC law. The European Commission does not indicate through the IPPC Directive that these techniques are mandatory for companies in the scope of the IPPC.

Table 1 shows that, in some cases, permits related to the landfill sector include specific requirements about the adoption of BAT. In particular, the majority of permits require the adoption of BAT with a deadline for implementation (37.3\% of cases). Another significant number of permits includes a description of BAT, but does not include specific prescriptions.

Table 1. Requirements about Best Available Techniques included in permits of landfills

\begin{tabular}{|c|c|}
\hline \multicolumn{2}{|c|}{ Best Available Techniques (BAT) } \\
\hline $\begin{array}{c}\text { IPPC Permit does not include the adoption } \\
\text { of BATs }\end{array}$ & $18.6 \%$ \\
\hline $\begin{array}{c}\text { IPPC Permit includes a description of BATs } \\
\text { but does not include specific requirements }\end{array}$ & $30.5 \%$ \\
\hline $\begin{array}{c}\text { IPPC Permit states that it has included } \\
\text { BATs for environmental purposes }\end{array}$ & $13.6 \%$ \\
\hline $\begin{array}{c}\text { IPPC Permit includes the adoption of BATs } \\
\text { with a deadline to be implemented }\end{array}$ & $37.3 \%$ \\
\hline
\end{tabular}


The data show that the approach regarding the Best Available Techniques indicated by the European Commission, in most cases was not considered. Table 1 demonstrates that one of the key tools of the European integrated permitting system (BAT) is not always used correctly by the competent authorities when issuing permits.

\subsection{Landfill water emissions requirements}

Our study also considers the Emission Limit Values related to water emissions (Table 2). For water emissions we refer to the run-off water from the landfill, being the leachate managed as liquid waste by the sample considered. We investigated the limit applied to the water emissions discharged in surface water. The data related to the discharge into sewers were not considered relevant for our aims due to the different limits often imposed by the local sewer management organization.

\section{Table 2. Emission Limit Values for landfills water emissions}

\begin{tabular}{|c|c|c|c|c|}
\hline \multicolumn{5}{|c|}{$\begin{array}{l}\text { Emission Limit Values related to waste water emis- } \\
\text { sions }\end{array}$} \\
\hline \multicolumn{5}{|c|}{ Destination: surface water } \\
\hline $\begin{array}{l}\text { Pollutants } \\
\text { (mg/l) }\end{array}$ & COD & TSS & Sulphate & $\begin{array}{l}\text { Number of } \\
\text { permits }\end{array}$ \\
\hline Valencia & 125 & 60 & 250 & 1 \\
\hline $\begin{array}{l}\text { West Ma- } \\
\text { cedonia }\end{array}$ & 125 & 25 & 250 & 3 \\
\hline Andalusia & n.a. ${ }^{1}$ & n.a. & n.a. & n.a \\
\hline Piedmont & n.a. & n.a. & n.a. & n.a \\
\hline Sicily & 160 & 80 & 1000 & 6 \\
\hline Tuscany & 160 & 80 & 1000 & 4 \\
\hline
\end{tabular}

The most important difference found in the data is related to sulphate pollutants. In West Macedonia and Valencia, we see a stricter limit than in Italy. Similar data was found for the Chemical Oxygen Demand (COD) and Total Suspended Solids (TSS) for which the Italian permits allow the discharge of wastewater with a higher pollutant load.

The data on ELVs for water discharge are not available for the regions of Andalusia and Piedmont,.

In table 3, we indicate the monitoring frequencies required by the permits for all parameters indicated in Table 2.

\footnotetext{
${ }^{1}$ Not available.
}

Table 3. Monitoring frequencies of landfills water emissions

\begin{tabular}{|c|c|c|}
\hline \multicolumn{2}{|c|}{$\begin{array}{c}\text { Monitoring frequencies of water emissions (with indi- } \\
\text { cations of number of permits) }\end{array}$} \\
\hline \multicolumn{2}{|c|}{} & $\begin{array}{c}\text { Number of per- } \\
\text { mits }\end{array}$ \\
\hline Valencia & n.a & n.a. \\
\hline $\begin{array}{c}\text { West Ma- } \\
\text { cedonia }\end{array}$ & Three-monthly & 3 \\
\hline Andalusia & n.a. & n.a. \\
\hline Piedmont & Yearly & 5 \\
\hline Sicily & Three-monthly & 6 \\
\hline \multirow{2}{*}{ Tuscany } & Monthly & 1 \\
\cline { 2 - 3 } & Three-monthly & 5 \\
\hline
\end{tabular}

The most frequent monitoring frequency is quarterly. There are differences among regions in establishing monitoring frequencies: the highest frequency is monthly (Tuscany) while the lowest is yearly (Piedmont). Also within the same region (Tuscany), the frequency may differ within different permits.

\subsection{Noise emissions monitoring frequencies}

Another important aspect to consider involves noise emissions. In this case, Emission Limit Values are not set either in the national regulation or in IPPC permits, but they are generally defined by local planning decided at the municipal level in order to account for the urbanization of local areas. Therefore, the most interesting data to analyse is how frequently the landfills are required to carry out new acoustic impact assessments at the perimeter of the plant in order to measure the noise emitted by the process. The frequency of impact assessments is linked to ordinary impact assessments. By ordinary, we mean that the impact assessment must be carried out even in the absence of significant modifications to the installations or to the production process. Data referring to permits are included in Table 4.

\section{Table 4. Monitoring frequencies of noise emissions}

\begin{tabular}{|c|c|}
\hline \multicolumn{2}{|c|}{$\begin{array}{l}\text { Monitoring frequencies of noise emissions (sector } 5.4 \\
\text { landfills) }\end{array}$} \\
\hline Andalusia & Frequency not established (100\%) \\
\hline Valencia & Five-yearly (100\%) \\
\hline $\begin{array}{l}\text { West Mace- } \\
\text { donia }\end{array}$ & Frequency not established (100\%) \\
\hline \multirow{4}{*}{ Piedmont } & More times a year (15.4\%) \\
\hline & Yearly $(53.8 \%)$ \\
\hline & Two-yearly $(7.7 \%)$ \\
\hline & Three-yearly $(23.1 \%)$ \\
\hline Sicily & Not available \\
\hline
\end{tabular}




\begin{tabular}{|c|c|}
\hline \multirow{4}{*}{ Tuscany } & Yearly (6.3\%) \\
\cline { 2 - 2 } & Two-yearly (25\%) \\
\cline { 2 - 2 } & Three-yearly (12.5\%) \\
\cline { 2 - 2 } & Frequency not established (56.3\%) \\
\hline
\end{tabular}

Table results show that there are large differences regarding these aspects among different regions. For example, in Andalusia and West Macedonia, no monitoring frequencies of noise emissions have been established at all. Moreover, in Italian regions (Tuscany and Piedmont), the frequency varies considerably. For example, in Piedmont in $15.4 \%$ of the cases, there is a monitoring frequency several times a year, in more than $53 \%$ of the cases the frequency is annual, and in the remaining cases, it is biennial (7.7\%) and triennial $(23.1 \%)$. Both in Piedmont and in Tuscany, there is a significant variation in the monitoring frequencies of noise emissions for landfill companies. Finally, in Valencia, the monitoring frequency always takes place every five years. These data show large disparities not only among different European regions, but also within the same region.

\subsection{Administrative fees for permitting pro- cedures and inspections}

Another aspect we investigated deals with the fees that companies with an IPPC permit should pay. Industrial companies have to pay a fee for the preliminary inquiries about the issuing and updating of substantial changes to the permit, and also following the re-examination. Moreover, there are also fees for the preliminary inquiries linked to permit renewal. Finally, fees also have to be paid for preliminary inquiries in the case of non-substantial changes, and also following the re-examination.

With regard to the amount of fees that enterprises must pay for the administrative procedure, wide differences exist among the regions.

In the case of Andalusia, the fee ranges from 1000 and 1500 Euros.

In Valencia, the administrative procedure for obtaining the integrated permit is free for companies.

In Piedmont, Sicily, and Tuscany, a national law regulates the accounting conditions and the applicable fees.

In the case of fees for preliminary inquiries about the issuing and updating of substantial changes, there are different fees that depend on certain elements (e.g. the installation typology, the number of emission points/discharges and the number of pollutants emitted by the activity, tons of waste). Some reductions in fees are foreseen by law.

Also, in the case of fees for preliminary inquiries linked to permit renewal, national legislation foresees different fees that depend on certain elements (e.g. the installation typology, the number of emission points/discharges and the number of pollutants emitted by the activity, tons of waste). Some reduction in fees is foreseen by law.

In the case of Piedmont and Tuscany, the actual fee can vary from 2,000 to 35,000 Euros, as stated by the competent authorities interviewed.

In West Macedonia, the fee is increased proportionally in accordance with installed power and activity or storage capacity. The fee is doubled if the authorisation is granted after the decision to interrupt operations. Specific amounts are not established.

Table 5 indicates fees that enterprises must pay for the administrative procedure.

\section{Table 5. Fares that enterprises must pay for} the administrative procedure

\begin{tabular}{|c|c|c|c|c|c|c|}
\hline \multirow{2}{*}{$\begin{array}{l}\text { State/ } \\
\text { Region }\end{array}$} & \multicolumn{2}{|c|}{ Spain } & \multirow{2}{*}{$\begin{array}{c}\text { Greece } \\
\text { West } \\
\text { Macedonia }\end{array}$} & \multicolumn{3}{|c|}{ Italy } \\
\hline & Andalusia & Valencia & & Piedmont & Sicily & Tuscany \\
\hline $\begin{array}{l}\text { Any fare to } \\
\text { pay }\end{array}$ & & $x$ & & & & \\
\hline $\begin{array}{l}\text { National law } \\
\text { establishing } \\
\text { fares }\end{array}$ & & & & $x$ & $x$ & $x$ \\
\hline $\begin{array}{c}\text { Regional } \\
\text { law } \\
\text { establishing } \\
\text { fares }\end{array}$ & $x$ & & & $x$ & & $x$ \\
\hline $\begin{array}{l}\text { Law does } \\
\text { not refer to } \\
\text { specific } \\
\text { amount }\end{array}$ & & & $x$ & & & \\
\hline $\begin{array}{l}\text { Some fare's } \\
\text { reductions } \\
\text { are } \\
\text { provided by } \\
\text { law }\end{array}$ & $x$ & & & $x$ & $x$ & $x$ \\
\hline
\end{tabular}

With regard to the amount of public fees that enterprises have to pay for inspections, there are many differences among regions, as in the case of fees for the permitting procedure. In Andalusia, inspections are subject to tax. The calculation of tax depends upon the content of the audits as they are detailed for each specific case in the annex relating to the "Control and Monitoring Plans". The charge for inspections, depending on whether they involve sampling, is as follows:

- $\quad$ Basic inspection without sampling: $€ .750 .00$

- Special inspection without sampling: €1,050.00.

- When it is deemed necessary to take samples and carry out analysis, the charge will be calculated using a specific formula.

No reduction exists for organizations that have been certified with an Environmental Management System (granted the international UNE-EN ISO 14001 and/or EMAS), although it is required for installations for intensive rearing of poultry or pigs, the applicable charge for inspections for the IPPC Permit will be $50 \%$ of the fee.

In Valencia, the inspections carried out by the IPPC officers are free for companies. The fees for inspections carried out by the Environmental Quality Collaborating Entities are approximately: 400-500 € per permit; 800-850 €/day of inspection.

In Tuscany, Piedmont and Sicily, a national law also regulates the accounting conditions and the fees to apply regarding controls. The legislation identifies: 
- fees concerning the activities that must be carried out in each inspection. There are different fees that depend on certain elements (e.g. the number of emission points/discharges and the number of pollutants emitted by the activity, tons of waste).

- fees concerning inspections arising from the possible programming of samples and analysis.

Some reductions in fees are foreseen for particular categories of enterprises. In West Macedonia, the inspections that the authorites carry out are free of charge for enterprises. Fees are only foreseen in the case of fines after the inspections and during the permitting procedure.

Table 6 indicates the fees for inspections in the six regions involved.

Table 6. Fares that enterprises must pay for inspections

\begin{tabular}{|c|c|c|c|c|c|c|}
\hline \multicolumn{7}{|c|}{ Fares that enterprises must pay for inspections } \\
\hline \multirow{2}{*}{$\begin{array}{c}\text { State/ } \\
\text { Region }\end{array}$} & \multicolumn{2}{|c|}{ Spain } & Greece & \multicolumn{3}{|c|}{ Italy } \\
\cline { 2 - 7 } & Andalusia & Valencia & $\begin{array}{c}\text { West } \\
\text { Macedonia }\end{array}$ & Piedmont & Sicily & Tuscany \\
\hline $\begin{array}{c}\text { Fares are } \\
\text { applied for } \\
\text { controls and } \\
\text { inspections }\end{array}$ & $\mathrm{X}$ & $\mathrm{X}^{1}$ & & $\mathrm{x}$ & $\mathrm{x}$ & $\mathrm{X}$ \\
\hline $\begin{array}{c}\text { Fares are } \\
\text { not applied } \\
\text { for controls } \\
\text { and } \\
\text { inspections }\end{array}$ & & $\mathrm{X}^{2}$ & $\mathrm{X}$ & & & \\
\hline
\end{tabular}

\subsection{The planning of on-site inspections}

In Andalusia, the type of inspection, as well as the frequency, methodology and the person responsible for carrying it out are defined in the Annex of the IPPC Permits entitled "Control and Monitoring Plans". In addition to these inspections, the Provincial Delegation of the Regional Government for the Environment, within its territorial scope, can access the installations at any time and without prior notice, in order to carry out any inspections deemed appropriate to verify compliance with the conditions imposed under the IPPC Permit.

The implementation of these inspections is regulated by the Sector Plans for Environmental Inspections. These plans are imposed by the application of the specified environmental standard and aimed at verifying the adequacy of the applicable environmental requirements in production sectors and the definition of measures needed to correct any anomalies. Sector Plans encompass all the programming inspections to be carried out by the technical personnel of the Department of Environment. In Andalusia, installations for intensive rearing of poultry or pigs are exempt from audits. In Valencia, all inspections planned during the validity of the permit are defined in the content of the permit and how often they are carried out depends on each parameter. The installations are required to send an annual report on the results of the monitoring plan to the competent authority. Prior to starting the activity, the operator should obtain authorization to commence the activity from the competent authority regardless of the need to obtain building permits required under municipal legislation. The operator has a maximum of three years to submit an application for authorization to start the activity to the competent authority, which must be accompanied by specific documentation. Once this documentation has been submitted, an initial inspection will be carried out by an Environmental Quality Collaborating Entity accredited in the IPPC field. After that, the competent authority will issue a permit to start the activity.

In Tuscany, with regard to planned inspections, the large number of competent authorities for controls and inspections means there is a significant difference in the number of planned inspections among provinces. In West Macedonia, the permit does not determine the number of inspections during the validity period of the permit. In light of these results, we can affirm that the IPPC Directive impacts the management of industrial companies. Figure 1 shows how the IPPC Directive can influence company costs in different ways and, as a consequence, its competitiveness

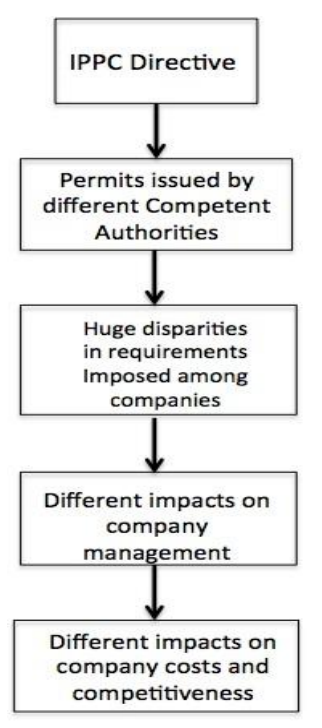

\section{Figure 1. Illustration on how IPPC Directive impacts on management of industrial companies}

\section{Discussion}

The European Directives must be implemented by the Member States. The Maastricht Treaty provides that the Member States shall choose the methods and actions for the implementation of the Directives. In addition, the IPPC Directive introduces the "flexibility principle" (art. 9 of the IPPC Directive) concerning the procedure to impose the ELVs in the IPPC permit. In particular, the article states that: "the Emission Limit Values and the equivalent parameters and technical measures referred to (. . .) shall be 
based on the best available techniques, without prescribing the use of any technique or specific technology, but taking into account the technical characteristics of the installation concerned, its geographical location and the local environmental conditions'. According to the Maastricht Treaty, competent authorities have the flexibility to define the content of IPPC permits, although within this flexibility, some key elements - mentioned above- should be considered. In the opinion of the authors, many of the differences highlighted in this paper cannot be justified despite these opportunities for flexibility. The ELVs of water discharges sometimes vary excessively among the competent authorities of different countries. The different levels in the ELVs influence the adoption of BAT in different ways, thus causing differences in the subsequent prevention of pollution, the key principle of the Directive. Also, the monitoring frequencies of emissions, especially in the case of noise, varies greatly, not only among different European regions, but also within the same regions. A monitoring frequency that fluctuates from once a year to every three years within the same region cannot be justified by the flexibility principle of the $\mathrm{Di}$ rective, especially if we also take into account that, in the same region, quite often no monitoring frequency for emissions has been established at all. Even if landfill companies differ from one another, in the authors' opinion, the differences among companies in the same industrial sectors are not enough to justify these significant disparities in some requirements imposed by the IPPC permit.

As a result we can conclude that the flexibility principle is not applied correctly. Moreover, some of the competent authorities interviewed stated that they are not entirely sure how to apply the flexibility allowed by the Directive and this supports our conclusions.

The authors believe that the current disparities in the implementation of the Directive can be linked to several reasons. Firstly, the Directive seems to give too much flexibility over the issuing of integrated permitting. This results not only from the flexibility principle, but also from the fact that the indications concerning assessment frequencies and the content of permits are too general. To overcome this problem, it would be advisable to encourage a more coordinated implementation of the Directive among the Member States.

A second reason for these disparities can be found in the weak coordination between the Member States at European level, and in the weak coordination between the different regions at a national level. At European level, the European Commission carried out periodic monitoring of the implementation of the IPPC Directive, requesting information from the national authorities of each Member State. However, the aim of these reports was simply to monitor the administrative issues regarding the implementation of the IPPC permits (e.g. the number of permits issued, the number of inspections carried out) and not the content of the permits themselves. If such monitoring were also extended to this area, the European Commission would be able to adopt actions to improve the uniformity of the permits. In addition, differences observed at regional levels suggest that when the coordination is managed by national ministries, it is not very effective.

Finally, some other reasons for disparities in the permitting systems can be linked to a lack of resources, mainly human resources, in the local competent authorities in charge of issuing the permits. In fact, the implementation of Emission Limit Values, covering the "technical characteristics of the installation concerned, its geographical location and the local environmental conditions" required increased knowledge and meant that public officials had to dedicate more time to issuing permits than when ordinary procedures were followed. Competent authorities are not always able to invest in the training of their employees and do not always have enough time to identify different ELVs for each installation. For this reason, the ordinary procedure is followed for IPPC as well, which means the ELVs identified in the national laws are included in the permits.

\section{Conclusions}

The results achieved by this paper contribute to the literature framework on the effects of environmental regulation. The paper concerns the content analysis of IPPC integrated permits. No previous studies on this topic have been published previously, and as mentioned above, the institutional monitoring performed by the European Commission does not have the same aims either. The study confirms that the Directive is implemented in different ways. As already observed by some authors regarding the different implementation of BAT [22, 10, 11, 23], our paper also confirms that other significant key principles of the Directive, such as the flexibility principle, could be better implemented.

The data shown in this paper reveal differences in IPPC permits across European regions linked to ELVs and monitoring frequencies. Moreover, companies have to pay very different fees for the administrative procedure and control inspections, and in some cases, no fee has to be paid. Also, the number of planned on-site inspections varies across companies.

Huge differences in the implementation of IPPC requirements for companies could cause different impacts on their environmental management. In particular, compliance with legislation generates costs that companies have to sustain. If requirements to comply with the Directive vary excessively among companies in the same sector, they could sustain different costs. This aspect could cause different impacts in landfill companies. The monitoring of emissions entails high costs and often involves external 
laboratories. Less frequent monitoring programs mean lower costs for landfills giving companies a competitive advantage. Therefore, in light of the research question and the results obtained, we can assume that the issuing of integrated permits by different European regions may bring about significant disparities in the environmental management of companies and in the compliance costs associated with them. To confirm this hypothesis, it would be necessary to carry out further studies on similar topics by collecting permits from other Member States and other European regions or linking the research to other industrial sectors within the scope of IPPC.

We invite scholars to take this research further. Some ideas for further analysis are linked to the assessment of the impacts of the disparities pointed out. For example, future research could assess the economic impact of these differences and their effects on costs and competitiveness. Further research could be developed which would assess the future implementation of IED. As mentioned above, the new Directive includes some new requirements in terms of the identification of ELVs (e.g. art. 15). Therefore, the effectiveness of these new requirements in eliminating disparities will have to be demonstrated.

\section{References}

[1] European Commission. (1996) Council Directive 96/61/EC of 24 September 1996 concerning integrated pollution prevention and control, Brussels, European Union.

[2] T. Daddi, M.R. De Giacomo, F. Testa, F. Iraldo, M. Frey. "The Effects of Integrated Pollution Prevention and Control (IPPC) Regulation on Company Management and Competitiveness". Business Strategy and the Environment. In press.

[3] T. Daddi, M.R. De Giacomo, G., Rodríguez Lepe, V.L. Vázquez Calvo, E. Dils and L. Goovaerts (2012) “A method to implement BAT (Best Available Techniques) in South Mediterranean countries: the experience of BAT4MED project", Environmental Economics, Vol. 3 No. 4, pp.65-74.

[4] G. Giner-Santoja, P. Aragonés-Beltrán and J. NiclósFerragut (2012) "The application of the analytic network process to the assessment of best available techniques", Journal of Cleaner Production, Vol. 25 No. 1, pp.86-95

[5] J. Geldermann, O. Rentz (2004) "The reference installation approach for the techno-economic assessment of emission abatement options and the determination of BAT according to the IPPC-directive", Journal of Cleaner Production, Vol. 12 No. 4, pp.389-402.

[6] C. Polders, L. Van den Abeele, A. Derden and D. Huybrechts, D. (2012) "Methodology for determining emission levels associated with the best available techniques for industrial waste water", Journal of Cleaner Production, Vol. 29-30, pp.113-121.

[7] A. Cikankowitz and V. Laforest (2012) "Using BAT performance as an evaluation method of techniques", Journal of Cleaner Production, doi: 10.1016/j.jclepro.2012.10.005
[8] T. Bréchet and H. Tulkens (2009) "Beyond BAT: selecting optimal combinations of available techniques, with an example from the limestone industry", Journal of Environmental Management, Vol. 90 No. 5, pp.1790-1801.

[9] G. Mavrotas, E. Georgopoulou, S. Mirasgedis, Y. Sarafidis, D. Lalas, V. Hontou and N. Gakis, N. (2007) "An integrated approach for the selection of Best Available Techniques (BAT) for the industries in the greater Athens area using multi-objective combinatorial optimization", Energy Economics, Vol. 29, No. 4, pp.953-973.

[10] A.M. Kocabas, H. Yukseler, F.B. Dilek and U. Yetis (2009) "Adoption of European Union's IPPC Directive to a textile mill: analysis of water and energy consumption", Journal of Environmental Management, Vol. 91 No. 1, pp.102-113.

[11]M.C. Barros, A. Magán, S. Valiño, M.P. Bello, J.J. Casares and J.M. Blanco (2009) "Identification of Best Available Techniques in the seafood industry: case study", Journal of Cleaner Production, Vol. 17 No. 3, pp.391 399.

[12] J. Geldermann, N.H. Peters, S. Nunge, O. Rentz (2004) "Best available techniques in the sector of adhesives application", International Journal of Adhesion and Adhesives, Vol. 24 No. 1, pp.85-91.

[13] D. Styles, K. O'Brien and M. Jones (2009) “A quantitative integrated assessment of pollution prevention achieved by Integrated Pollution Prevention Control licensing", Environment International, Vol. 35 No. 8, pp.1177-1187.

[14] T. Daddi, M. Magistrelli, M. Frey, F. Iraldo, (2011). "Do Environmental Management Systems improve environmental performance? Empirical evidence from Italian companies". Environment, Development And Sustainability, Vol. 13 No. 5, pp.845-862.

[15] N. Honkasalo, H. Rodhe and C. Dalhammar (2005) "Environmental permitting as a driver for eco-efficiency in the dairy industry: A closer look at the IPPC directive", Journal of Cleaner Production, Vol. 13 No. 10-11, pp.1049-1060.

[16] K. Silvo, T. Jouttijärvi and M. Melanen (2009) "Implications of regulation based on the IPPC Directive - A review on the Finnish pulp and paper industry", Journal of cleaner production, Vol. 17 No. 8, pp.713-723.

[17] M. Battaglia, L. Bianchi, M. Frey, F. Iraldo (2010) "An innovative model to promote CSR among SMEs operating in industrial clusters: evidence from an EU project", Corporate Social Responsibility and Environmental Management, No 17, pp.133-141.

[18] B. Berelson (1952) Content Analysis in Communication Research, Free Press, New York.

[19] GAO, U.S. General Accounting Office. (1996) Content Analysis: A Methodology for Structuring and Analyzing Written Material, Washington, D.C.

[20] K. Krippendorff (1980) Content Analysis: An Introduction to Its Methodology, 4th ed., Newbury Park, Sage.

[21] Weber RP. 1990. Basic Content Analysis. 2nd edition (Sage, Newbury Park, CA).

[22] M.C. Barros, P. Bello, E. Roca and J.J. Casares (2007) "Integrated pollution prevention and control for heavy ceramic industry in Galicia (NW Spain)", Journal of Hazardous Materials, Vol. 141 No. 3, pp.680-692.

[23] C. Vazquez, G. Rodríguez, T. Daddi, M.R. De Giacomo, C. Polders, E. Dils (in press). "Policy challenges in 
International Journal of Sustainable Energy Development (IJSED), Volume 3, Issue 2, December 2014

transferring the integrated pollution prevention and control approach to southern mediterranean countries: a case study", Journal of Cleaner Production. Available on line at: http://dx.doi.org/10.1016/j.jclepro.2014.06 